\title{
El retorno de los judeoconversos portugueses en época del conde duque de Olivares
}

\section{The Return of the Portuguese Judeo- conversos in Times of Count Duke of Olivares}

\section{Shai Cohen}

Universidad de Granada

ESPAÑA

scohen64@gmail.com

[Hipogrifo, (issn: 2328-1308), Volumen extraordinario, 1, 2018, pp. 191-215]

Recibido: 07-08-2017 / Aceptado: 17-08-2017

DOI: http://dx.doi.org/10.13035/H.2018.extra01.14

Resumen. La comunidad judeoconversa de Portugal aumentó su influencia y riqueza durante el siglo XVI hasta tal punto que el mismo conde duque de Olivares les invitó durante sus años de privanza y les abrió las puertas del reino para aprovechar préstamos de bajo interés. La instalación de los banqueros portugueses en la Península formaba parte de una batería de medidas para sanear la economía de la monarquía. El valido recurrió a esta solución por varios motivos, entre ellos intentar reducir la dependencia gubernamental de los banqueros genoveses y darle un impulso al comercio utilizando las redes ya establecidas por los ricos mercaderes portugueses. Sin embargo, estas medidas se vieron afectadas por la cuestión religiosa y su enorme peso social. El hecho de que los banqueros portugueses fueran de origen judeoconverso provocó un grave conflicto entre el gobierno político y la autoridad religiosa.

Palabras clave. Judeoconversos; banqueros portugueses; conde duque de Olivares; crisis española; comercio; Inquisición; Siglo de Oro.

Abstract. The judeoconverso community in Portugal increased its influence and wealth during the sixteenth century to such an extent that the Count Duke of Olivares conceded them access to the kingdom. Olivares, favourite of Philip IV, made this 
controversial decision as one of the efforts to end a continuous state of economic decline by taking advantage of their low interest loans. Thus they became the Portuguese bankers in the Peninsula settling down in the metropolis and integrating in the local life. Olivares resorted to this solution trying to reduce government dependence on Genoese bankers and to boost trade and commerce using the networks already established by the rich Portuguese merchants. However, these measures were affected by the religious question and its enormous social weight. The Jewish origin of the bankers caused a serious conflict between the political government and the religious authority.

Keywords. Judeoconversos; Portuguese Bankers; Count Duke of Olivares; Seventeenth-Century Crisis; Trade; Jewish Merchants; Inquisition; Golden Age.

A lo largo de la segunda mitad del siglo XV Portugal extendió una compleja e importante red comercial en ultramar que le permitió confirmar su supremacía marítima'. Al mismo tiempo, los vecinos peninsulares igualmente se movilizaron y tras varias expediciones al sur, la reina de Castilla patrocinó el famoso viaje de Colón descubriendo un nuevo destino comercial. De tal modo que se abrió la vía a nuevas mercancías y emergió una nueva clase de emprendedores que se enriqueció rápidamente. Gran parte de esta nueva clase social estaba formada por emprendedores judíos, en su gran mayoría convertidos al cristianismo a lo largo del siglo XV.

El tópico de la relación de los judíos con el dinero se ha prestado siempre a un gran juego dialéctico que llega incluso a abarcar aspectos antropológicos y etnohistóricos². Por ello, las nuevas relaciones de la corona española con los asentistas portugueses de origen judeoconverso estuvieron siempre bajo la losa de sospechas preconcebidas sobre su sinceridad religiosa y lealtad al rey, además de un cierto odio ancestral y el binomio usura-judío acaudalado, como el caso de la mohatra, directamente vinculada con la transacción mercantil ${ }^{3}$.

Desde el siglo XIII, la doctrina cristiana prohibía el préstamo con interés a cristianos, recurriendo al subterfugio del préstamo amistoso sin consignar los inte-

\footnotetext{
1. Me refiero en particular a la costa africana y asiática, ya que los portuqueses habían establecido redes comerciales con Inglaterra, Francia y Países Bajos en el siglo XII, incluso prestando dinero a los nobles locales (Marques de Oliveira, 1972, p. 91). Ver igualmente la tesis de Carrasco Vázquez, 2004, p. 51 en adelante.

2. Varios investigadores han hablado del énfasis aparente y la problemática de relacionar el tema judío con lo económico. Ver en particular: Poliakov, 1965; Le Goff, 1991; Israel, 1992; Cánovas del Castillo, 1910; Roth, 1974, etc. Para el tema de los judíos en España, en general, ver Caro Baroja, 1961; Contreras, Pulido y Benítez, 2005; Lozano, 2002; León Tello, 1979, tomo I, p. 87 y adelante; Sloan, 2009; Adler, 1908; Pimenta Ferro Tavares, 1992; Castro, 1992.

3. La usura puede referirse en su definición amplia a prácticamente cualquier mercader-banquero. El uso restringido hacia los judíos era, evidentemente, para servir a fines antijudíos. Ver a propósito el artículo exhaustivo de Leroy, 1995.
} 
reses. Así que el judío (hasta entonces principalmente cambista y mercader) se transformó en el usurero por excelencia4 ${ }^{4}$. De modo que se extendió un descontento popular hacia los judíos, y en especial a los cristianos nuevos, acusándolos de usureros en sus préstamos 5 . Concluye Sloan:

Prohibition of this activity for Christians stemmed from the church dictum that charging interest for the loaning of money was immoral. Hinojoso Montalvo reminds us that «One of the deepest causes of anti-Semitism is to be found in usury, to the extent that the words usurer, Jew and enemy of Christ are used synonymously» ${ }^{6}$.

Es evidente que, pese a dichas leyes y prohibiciones, los cristianos y musulmanes se encargaban de los negocios y comercios de este tipo. Sin embargo, en el imaginario popular sólo la parte judía manejaba los hilos del dinero prestado por varios motivos ${ }^{7}$ pero destacando sobre todos la posición sociocultural de minoría que les dejaba al margen de la vida cotidiana y con pocas oportunidades, por ejemplo, no podían ejercer ciertas profesiones sin un permiso especial. Esta marginación, además de formar una comunidad propia, fue una razón de peso para dedicarse a los negocios y prestamos al nivel internacional, interconfesional e intercultural$^{8}$. Este contexto permitía que las monarquías europeas aceptaran préstamos a manera de excepción por necesidad; tal y como deduce Lapeyre un préstamo, sólo se admite cuando el estado es el prestatario'.

Las más sonadas conversiones masivas al cristianismo se produjeron en la Península en 1391, 1449 y hasta 1492, fecha de la expulsión de los judíos de los reinos de Castilla y Aragón. En Portugal, se produjo una conversión masiva en octubre de 1496, distinta de las conversiones españolas, ya que eran judíos más devotos y al mismo tiempo más desesperados debido a las medidas que impedían a muchos salir del país ${ }^{10}$. Así, según Soyer, se formaron alrededor de 60.000 nuevos cristia-

4. De hecho, la visión negativa del prestamista logrero empezó en el Antiguo Testamento (Deuteronomio, 23, 19-20, Éxodo, 22, 25 o Levítico, 25, 35-37: «No tomarás de tu hermano logro de dinero, ni logro de comida, ni logro de cosa alguna de que se suele tomar»). Referencia encontrada en Le Goff, 1991, p. 77. 5. Para más sobre este tema, ver Sáenz-Badillos, 2006. Entre los primeros reconocidos asentistas aparecieron personajes conocidos como el judío Isaac Abravanel, el consejero financiero, Gabriel Sánchez, Francisco Pinelo, Juan de Coloma, Rodrigo de Ulloa y Sancho de Toledo (Sloan, 2009, p. 83).

6. Sloan, 2009, p. 152.

7. De modo general los judíos no se dedicaban a la agricultura y la tradición de estudiar desde tierna edad era muy común (en lo denominado jéder, es decir, el aula de estudios para niños) y dio lugar a que muchos de la comunidad se educasen. Ver artículos sobre la vida judía en la época, por ejemplo el de Nahon, 1992.

8. Una posición que ellos compartían con los estados italianos desde el siglo XIII (Marques de Oliveira, 1972, p. 94)

9. Lapeyre, 1953, p. 13.

10. Hay que recordar que gran parte de las comunidades judías portuguesas constituían un número importante de judíos piadosos que se negaron a convertirse en el tiempo de la expulsión española cuatro años antes. 
nos $^{11}$. La diferencia entre la expulsión de los judíos de España y la de Portugal' ${ }^{12}$ por el rey Manuel I tuvo un impacto decisivo en el futuro de los judeoconversos. Don Manuel nunca tuvo la intención de expulsar a los judíos pues era consciente de lo beneficioso que era mantenerlos, sin embargo, terminó cediendo frente al chantaje de los Reyes Católicos negándole la mano de su hija, Isabel de Aragón. La intención de don Manuel nunca fue una depuración completa de la minoría judía, sino más bien convertir a los que pudiera, ocultar al resto y expulsar al menor número de judíos posible ${ }^{13}$. Con las conversiones forzosas, los cristianos nuevos ricos tomaron este papel de asentistas a cambio de beneficios comerciales y protecciones fiscales. Más tarde, ya en el siglo XVI, se añadió una nueva circunstancia: comenzaban a aparecer en las listas de los procesos inquisitoriales ${ }^{14}$. Algunos entre ellos eran asentistas portugueses de origen judío de dudosas prácticas religiosas y cuyos nombres figuraban siempre en el entorno de Felipe III y don Gaspar de Guzmán, conde duque de Olivares, valido de Felipe IV.

\section{COMERCIO Y ENRIQUECIMIENTO, MOTIVOS Y TRADICIÓN}

Bajo el reinado de Fernando el Católico, se estableció la nueva Inquisición. Sucesivamente, en 1481, según afirma García Cárcel, fue promulgado el concepto de la autodenuncia, Ilamado luego el Edicto de Gracia ${ }^{15}$. Los Edictos de Gracia fueron planteados estratégicamente en forma de una ceremonia del poder semejante a la del auto de fe que tenía la virtud de aterrorizar y engrandecer a la vez. Es decir, se trataba de implicar, con gravísimas amenazas, a aquellos que se sintieron concernidos para que confesaran, informaran y denunciaran a sus prójimos. Con el tiempo aumentaron las denuncias, las detenciones y, consecutivamente, los castigos (sociales, físicos y económicos), así que, al percatarse del beneficio económico, Fernando nombró en 1487 un abogado para recuperar de las manos inquisitoriales los bienes confiscados.

Paradójicamente, hasta la primera mitad del siglo XVII el número de los tribunales inquisitoriales no llegó a su auge ${ }^{16}$. La costumbre de juzgar delitos leves generó desconfianza en la veracidad y la eficacia del sistema inquisitorial durante su exis-

11. Entre los cuales 10.000-20.000 en la forzada conversión en el palacio Estaus (Soyer, 2007, pp. 219220).

12. Sobre la expulsión de los judíos de Portugal ver Soyer, 2007 (en particular capítulo IV, pp. 182-240) y Saraiva y Salomon, 2001.

13. Es la razón de algunas medidas radicales antes del decreto de expulsión en la fiesta judía de Hannuka (04/12/1496), como la que comenta Soyer de la separación de los niños judíos hasta la edad de catorce años de sus padres e instalarlos junto con las dos tercias partes de la herencia de sus padres en familias de cristianos viejos (Soyer, 2007, p. 210).

14. Soyer afirma que la Inquisición se instaló en Portugal en 1536 por razones puramente políticas; en particular, para devolver el poder sobre los ricos comerciantes a las manos de la nobleza (Soyer, 2007, en particular pp. 229-230).

15. García Cárcel, 1997, p. 33

16. Quince tribunales en Barcelona, Córdoba, Cuenca, Granada, Logroño, Llerena, Madrid, Murcia, Santiago, Sevilla, Toledo, Valencia, Valladolid, Palma y Zaragoza (Roth, 1974, p. 84). 
tencia, por lo que culparon a algunos inquisidores de aprovecharse de denuncias falsas para juzgar severamente delitos sin pruebas suficientes, algo que ocurría cada vez con mayor frecuencia. En un manuscrito del 16 de febrero del año 1646, un anónimo decidió enviar una queja al rey afirmando lo siguiente:

Habiendo dado V. M. forma en el fuero de la milicia reduciendo su privilegio al lugar y calidades con que le deben gozar, es de igual conveniencia y necesidad reformar los abusos que se han introducido por los ministros y oficiales de la Inquisición con pretexto de privilegio, en perjuicio de las ventas reales, desconsuelo de los vasallos de V. M. y perturbación de la paz pública. [...] Los inquisidores contravienen a ambas leyes, visando de pena espiritual en materia temporal, como lo son los privilegios reales que obtuvieron por gracia de V. M. contra la jurisdicción real, y en causa profana ${ }^{17}$.

Ebben se hace eco de los trabajos de Caro Baroja, Swetschinski y de Dedieu, y resume la confrontación de la Inquisición y el conde duque de Olivares ${ }^{18}$. La fluctuación en el número de procesos muestra los años de influencia del favorito sobre su rey y la política ${ }^{19}$. Por ello, cabe preguntarse cuánta importancia tuvo realmente el poder mercantilista judeoconverso sobre el desarrollo de la corona y el poder temporal. Tras revisar la Alegación, de Martín González de Cellorigo, J. I. Israel afirma de su prefacio que la conclusión del famoso arbitrista era que:

Urgía a la corona española para que frenase el hostigamiento a que la Inquisición sometía a los marranos portugueses emigrados a España, argumentando la necesidad a tolerarlos, e incluso alentarlos, en nombre de la razón de Estado, para las finanzas y el comercio español se vieran beneficiados ${ }^{20}$.

En realidad, no faltan precedentes para ejemplificar una situación donde, por necesidad económica, se paliaron estrictas perspectivas religiosas y políticas. Una famosa incidencia estuvo relacionada con el mismísimo papa Alejandro VI, cuando permitió entrar en el Vaticano a los judíos de la Península Ibérica tras la expulsión por los Reyes Católicos. El papa consintió el establecimiento de un gueto ${ }^{21}$ judío a cambio de una suma considerable de dinero y el incremento de los negocios. Más tarde, en el año 1589, el gobierno veneciano reconoció el potencial de los mercaderes judíos o bien judeoconversos (con procedencia de la Península Ibérica). De tal forma que se les concedieron nuevos permisos en forma del denominado Cinque Savii alla Mercanzia. Muchos mercaderes judeoconversos pudieron recuperar su religión y vivir en seguridad con libertad de movimiento. El gobierno veneciano firmó dicho acuerdo por diez años renovable con modificaciones hasta 1711 y tuvo el apoyo clerical en la persona de fra Paolo Sarpi, aplicando la raison d'état y poniendo

17. AHN, leg. 7122 , núm. 47

18. Ebben, 1993, p. 551

19. 1626-1630 y 1636-1640 fueron etapas marcadas por una mínima actividad inquisitorial por intervenciones del rey y su valido (Ebben, 1993, p. 552).

20. Israel, 1992, p. 79. La referencia en Alegación, según Israel, es González de Cellorigo, Alegación, prefacio y fol. $22 \mathrm{v}$.

21. Uso anacrónico de la palabra, aunque es más probable que fue creada para describir el mismo fin, en la misma ciudad y para el mismo pueblo. 
el bien común de los ciudadanos de la cita y el beneficio público por encima de las cuestiones ideológicas ${ }^{22}$.

Tras un siglo de oscilaciones en las posturas de ambos reinos, español y portugués, unidos en 1580, hacia su minoría judeoconversa, la crisis económica propició la entrada de los asentistas portugueses, sobre todo por los beneficiosos intereses que se derivaban de este acuerdo. Los genoveses sacaron ventajas de las enormes necesidades de ingresos en efectivo ${ }^{23}$, ya que les permitió establecer unos intereses muy elevados (en 1598-1599 fueron el 14,67\%) ${ }^{24}$. De modo que, al final de algunas décadas de malestar económico, en noviembre de 1629, se les concedió a los lusitanos de sangre manchada la completa libertad de movimiento.

Tanto para los banqueros como para los comerciantes y mercaderes judeoconversos surgió una doble oportunidad: en primer lugar, les permitió a algunos volver a la tierra de sus antepasados (tras cuatro generaciones en tierra lusitana); y en segundo lugar, pudieron afianzar la red comercial fortalecida en 1621 tras acabar la tregua de los doce años. Dicha red se extendió por casi todo el mundo, tanto el viejo como el nuevo (España, Portugal, Holanda, Francia, el imperio otomano y los corresponsales en Asia, África y las Indias). De hecho, es interesante notar, como hace Studnicki, que los comerciantes portugueses llegaron a arriesgar su identidad híbrida para aprovechar estos nexos mercantilistas de índole internacional y capitalista ${ }^{25}$ (o bien pre-capitalista, para no confundir con algunas interpretaciones más recientes del término ${ }^{26}$. La red se extendió no solamente por las familias judeoconversas, sino también por los mercaderes judíos nuevamente enriquecidos de la Europa septentrional que eran indispensables desde el punto de vista comercial y monetario. J. I. Israel estima el impacto del comercio judío y judeoconverso en la siguiente afirmación:

Sephardi Jewry in Europe and in the European overseas colonies was undoubtedly a major factor in economic, maritime and colonial expansion throughout the early modern era, from the late fifteenth century down to the French revolutionary wars. Sephardi Jews and crypto-Jews (especially in the Iberian Peninsula) contributed in several important respects to the growing ascendancy over international trade, shipping and finance of the leading European commercial centers of that time, especially Lisbon, Antwerp, Seville, Madrid, Salonika, Constantinople, Venice, Livorno (Leghorn), Amsterdam, Hamburg, Bordeaux and London²7.

22. Rabid, 1996, p. 77.

23. Los préstamos de las poderosas familias de los principados italianos a los distintos reinos europeos para financiar guerras no eran una novedad española: después de 1290, los Bardi y Peruzzi se mudaron a Londres para financiar las guerras del rey Eduardo III (Sampson, 1982, p. 27).

24. Ver en particular Boyajian, 1983, gráfico descriptivo p. 167.

25. Weber, en su espíritu capitalista, lo ilustra mediante la figura de Jacobo Fugger, quien, tras una satisfactoria ganancia, en vez de retirarla para compartirla con otros, confesó que su aspiración era ganar todo cuanto pudiera (Weber, 1985, p. 45). Si bien no se puede calificar a un mercader medieval como capitalista por sus métodos, el mercader-banquero es capitalista en su espíritu, género de vida y el lugar que ocupa en la sociedad (Le Goff, 1991, p. 45).

26. Studnicki-Gizbert, 2003, p. 629

27. Israel, 1992, pp. 365-398. 


\section{CRISIS ECONÓMICA EN ESPAÑA Y NECESIDAD MONETARIA DE BAJO INTERÉS}

En España, durante la primera mitad del siglo XVII, la situación económica llegó a ser precaria debido a una acumulación de acontecimientos ${ }^{28}$ entre los que destacan: una recesión agraria en varios lugares de los territorios españoles (15951601); el continuo descenso del comercio y disminución en la producción mineral proveniente de América (empeorado por la derrota de la Armada Invencible de 1588); fuerte despoblación; inversión en juros en vez de en actividad industrial y comercial; desproporcionados gastos bélicos; explotación de la economía española por el oficio de asentistas (en particular, los genoveses); la retirada de oro y plata; fuertes fluctuaciones debido a la desesperada política monetaria ${ }^{29}$; escasez de mano de obra ${ }^{30}$; las oleadas de peste y el declive de la industria y el cese comercial ${ }^{31}$, particularmente el eje Medina-Burgos-Países Bajos (esencialmente por la vuelta a las confrontaciones bélicas tras el final de la tregua de los doce años en $1621^{32}$ y el principio de la Guerra de los treinta años en 1618) ${ }^{33}$. Añádanse los constantes problemas a nivel local entre los nobles gobernantes y el rey, por ejemplo, a propósito del impuesto de millones (impuestos sobre productos de primera necesidad como aceite, sal, azúcar...), creado por Felipe II en 1591. Según reclamaban múltiples figuras destacadas, los millones no fueron sino un impedimento a la recuperación y crecimiento económico ${ }^{34}$.

Durante la primera mitad del siglo XVII, el intento del gobierno de Felipe III de integrarse en un esquema comercial global fracasó por una defectuosa organización económica ${ }^{35}$. La corona intentó recuperarse y volver a una relativa bonanza con las riquezas provenientes del Nuevo Mundo (con un auge en los años cincuenta del siglo XVI). En estos años, los vecinos europeos empezaron a aprovechar un movi-

28. Para un estudio detallado, ver Domínguez Ortiz, 1984; Elliott, 1991; Hamilton, 1984; G. Enciso, 1986; Colmeiro, 1965; Boyajian, 1983; García Guerra, 2006; Gutiérrez Nieto, 1996. Martín González de Cellorigo fue, sin duda, una de las fuentes esenciales tanto para los investigadores mencionados como para los propios arbitristas.

29. Hamilton (1984, pp. 136-137) lo recalca mediante una comparación entre las deflaciones de los precios durante la gran depresión del 1929 (en su mayor momento un 37.86\%) y lo ocurrido en varios momentos en el siglo XVII (un 87\% en septiembre de 1642). Para poner un ejemplo si en 1621 una docena de huevos costó 1.85 reales (Díez Borque, 2009, p. 59) en 1629 costó 1.68, luego a finales de 1641 costaría 3.25 para acabar un año más tarde con el pequeño precio de 0.42 reales (aunque probablemente dichas fluctuaciones no llegaron a ser tan significativas con los huevos sino que con productos más costosos y no de primera necesidad como ciertos metales y demás materia prima).

30. A pesar de los intentos de elevar el respeto hacia el trabajo industrial, económico y los oficios como señala Cavillac (2004).

31. Para conocer más sobre la cuestión, ver Palacio Atard, 1987, segunda parte, capítulo V.

32. Una de la razones es económica. Según Parker, España decidió terminar la tregua por miedo de la consolidación comercial de sus territorios (Parker, 1977, p. 264).

33. Etreros, 1977, p. 173.

34. Una de ellas era el toledano Jerónimo de Ceballos, quien abogaba por la abolición de este impuesto ineficaz; ver Elliott, 1991, pp. 138-139, 163-164.

35. Ruiz Martín expone una exhaustiva elaboración del tema de las finanzas (Ruiz Martín, 1990, p. 193). 
miento expansivo del desarrollo de la industria ${ }^{36}$, lo que en España ocurrió en pocas ciudades ${ }^{37}$ (sobre todo Madrid, Sevilla y Barcelona). Por ende, para contrarrestar los efectos destructivos de la crisis, los economistas y administradores bajo el mando de Francisco de Sandoval y Rojas, el Duque de Lerma, tomaron varias medidas recaudatorias. Algunas de estas son las ordenanzas y previsiones de forma variada de impuestos, servicios y ventas de cargos y oficios públicos ${ }^{38}$.

Como consecuencia directa de los múltiples gastos y el conservadurismo comercial e industrial hubo tres bancarrotas sólo durante la primera mitad del siglo XVII (1607, 1627 y 1647), en las que había que suspender los pagos y conceder grandes favores que a continuación pesaron sobre un posible saneamiento económico ${ }^{39}$. Para evitar una derrota, había que continuar con las fuentes habituales de ingresos, incluyendo recaudación de los tributos, impuestos (alcabalas, los servicios y montazgo, rentas, aduanas, papel sellado), servicios ordinarios y extraordinarios (los millones), diferentes contribucione y donativos (eclesiásticos, comerciantes y privados), las agotadas remesas procedentes de las Indias y más.

Así, un autor anónimo expresa de esta forma su queja:

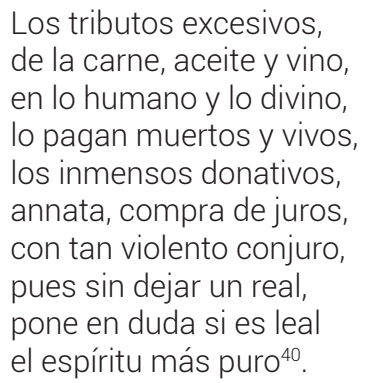

Olivares igualmente permitió la creación de la banca apoyada por el estado. Así, con el razonamiento de mejor seguridad y flujo de dinero y comercio americano, se creó en 1621 una red de Bancos de Estado y una armada nacional permanente de treinta mil hombres ${ }^{41}$. Estos bancos estatales son los famosos Erarios Públicos, proyecto promulgado por Pedro Oudegherste y Luis Valle de la Cerda. El plan fue crear, a base del tesoro público acumulado mediante los impuestos, una organización bancaria estatal apoyando un sistema que fue establecido para ordenar

36. Me refiero más a la noción más moderna de la palabra. 0 sea, instalaciones para facilitar fabricaciones y laborar materia prima.

37. Dubois, 1970, p. 101

38. Domínguez Ortiz, 1984, pp. 30-32. Sobre la venta de cargos y oficios ver pp. 171-178.

39. Gelabert, 1998, p. 266. Ver igualmente Ruiz Martín, 2008, pp. 80-84.

40. El extracto ilustra la expresión cómica de la situación. La décima aparece editada y anotada en mi trabajo El poder de la palabra: la sátira política contra el Conde Duque de Olivares (poema núm. 18, vv. 11-20) en prensa.

41. Elliott y de la Peña, 1978, tomo I, p. 174 
y reconstruir la decadente economía ${ }^{42}$. Aparentemente, al organizar el proceso se revelaban los fallos, uno de los cuales radicaba en el problema de la despoblación, en parte por la expulsión de los moriscos en 1609, que dejó multitud de campos sin rendimiento.

La multiplicación de los juros y asientos iban igualmente vaciando las arcas imperiales. Por ejemplo, la deuda creció tanto que en el año 1629, sus cargos suponían más de 8.000.000 de ducados, de la mayoría de gastos de 15.400 .000 ducados para todo el gobierno ${ }^{43}$. Es decir, la deuda llegó a ser más de la mitad de los gastos de la monarquía. De tal forma se afianzó un círculo vicioso alrededor de la falta de dinero como incentivo para el comercio, agricultura y renovación de los arcaicos sistemas de recaudación y regeneración fiscal.

El valido modificó la organización del centro logístico global donde se encontraba la red que manejaba la actividad comercial desde su aspecto burocrático. En parte, estableció y afianzó diferentes Juntas para sobrepasar el obstáculo mayor para sus ambiciosos planes, es decir, los Consejos. En las mencionadas Juntas puso gente de confianza que le proporcionó el apoyo deseado para llevar a cabo sus reformas. Las Juntas trataron de diversos asuntos: Junta de la Armada, de Comercio, de Reformación, del Almirantazgo, de Minas, de Población y Comercio, Juntas de Ejecución y Obediencia. Elliott y Borrego Pérez señalan que a finales de 1643 había más de treinta ${ }^{44}$. Un poema satírico de la época muestra la expresión del pueblo frente a estas medidas:

$$
\begin{aligned}
& \text { Reformad de tanta junta } \\
& \text { conciliábulos secretos, } \\
& \text { aplicando sus discursos, } \\
& \text { a sus nativos consejos. } \\
& \text { Obren sólo por justicia, } \\
& \text { pues es viviente derecho, } \\
& \text { tan acertado puntal } \\
& \text { como muestra Chumacero. }
\end{aligned}
$$

Otro intento fallido de salvar las arcas del reino fue en el campo monetario. El 7 de agosto de 1628, el conde duque promulgó y ejecutó la reacuñación de la sobreusada moneda de vellón y se retiró la parte de la plata dejando el cobre como el metal dominante. La moneda perdió el cincuenta por ciento de su valor inicial causando el encarecimiento del coste de vida (incluso de los precios de los productos básicos como pan y sal) $)^{45}$.

La visión económica del valido le impulsó a empeñar una serie de decisiones como el decreto de varias contribuciones pecuniarias para la recaudación (por

42. En cuanto a los erarios, menciono sólo el dato relevante para esta investigación, es decir, el banco. Para más datos, ver Cavillac, 2004, p. 277 y Palacio Atard, 1987, p. 112.

43. Hernández, 2009, p. 21.

44. Borrego Pérez, 2009, p. 86. Igualmente ver Elliott, 1991, p. 470.

45. Ver al propósito Elliott, 1991, pp. 311-312; García Guerra, 1998; Gelabert González, 1998; Hamilton, 1984; Hernández, 2009, entre otros. 
ejemplo, el servicio de lanzas ${ }^{46}$, establecido en 1631, la conmutación de penas y más). Sin embargo, este trabajo va a tratar de una medida en particular: la decisión de contratar a los banqueros portugueses de origen judeoconverso como asentistas tras ir rompiendo los estrechos enlaces con los genoveses. El acicate principal se mudó desde la visión religiosa en relación con el manejo del dinero hasta las medidas hechas para acordarlos el libre movimiento en el territorio. Aquella sustitución de los banqueros genoveses era un paso estratégico, capaz de contribuir a la recuperación económica de la monarquía pero como vamos a ver, en la práctica no fue tan simple.

\section{GOBIERNO, INQUISICIÓN Y OLIVARES, RELACIONES CON LOS BANQUEROS LUSITANOS}

El arbitrista Duarte Gomes Solis respaldó las medidas relacionadas con los conversos portugueses y su importancia económica para España ${ }^{47}$. Dada su procedencia y profesión fue el portavoz de la clase comerciante conversa; abogaba por la cooperación y provecho mutuo ${ }^{48}$. De hecho, este portugués de origen judío expuso ideas claves en sus Discursos sobre los comercios de las dos Indias (Madrid, 1622), algunas de las cuales llegaron a ser aprovechadas e incorporadas más tarde por el valido ${ }^{49}$. Su teoría mercantilista ${ }^{50}$ y consejos al rey se basaron en su extensa experiencia por los mares e importante saber sobre la teoría monetaria y la ciencia del comercio, destacándole entre los arbitristas ${ }^{51}$. Solis presenta un buen ejemplo no sólo como arbitrista con ideas prácticas para mejorar el sistema monetario y mercantil español, sino también para la mentalidad de los judeoconversos portugueses, en cuestiones relativas al comercio, pertenencia geográfica e identidad étnica y cultural.

La situación de los judeoconversos, en particular su seguridad y protección, corrió pareja con las fluctuaciones en el poder ejecutivo del conde duque. La nueva ola de episodios violentos impulsados por la Inquisición podría dar a entender que la influencia de Olivares sobre el rey había disminuido ${ }^{52}$. Al principio de su valimiento destacaba la estrecha relación entre él y los judeoconversos, ilustrada con la figura

46. Aunque el servicio de lanzas aportó menos de la mitad de lo estimado por el valido (Hernández, 2009, p. 29)

47. Sobre el tema de los arbitristas ver Cohen, 2013.

48. Gutiérrez Nieto, 1996, p. 435

49. Elliott y de la Peña, 1978, tomo I, p. 46. Se trata, entre otras ideas, de la unión de la Monarquía, abolición de los puertos secos, fomento de las armadas, extinción del vellón, abolición de los millones, dedicación al comercio.

50. Wachtel recuerda que, a pesar de que el término teoría mercantilista no existía antes de 1773 , el análisis de Gómez Solís detalla formas de expansión mercantil, técnicas metalúrgicas para tratar con el comercio de metales preciosos, técnicas de navegación y demás innovaciones (Wachtel, 2011, pp. 171-182)

51. Wachtel revisa en su artículo los trabajos más importante de Solis (Discursos...y Alegación a favor de la compañía de la India oriental. Y comercio ultramarino, que de nuevo se instituyó en el reino de Portugal). Ver en particular Wachtel, 2011, pp. 172-182.

52. Por ejemplo, la participación de Olivares en el Cristo de la Paciencia, el gran auto de fe llevado a cabo en la Plaza Mayor en 1632. Fue una muestra de un cambio en la relación hacia los judeoconversos. 
de Manuel López Pereira, su consejero económico (y partidario de Duarte Gomes). López Pereira había propuesto en 1624 una mutación drástica de la Carrera de Indias y a través de sus obras impresas tanto él como Duarte Gomes mantuvieron proyectos ambiciosos para su entorno social proponiendo como base la completa libertad de comercio en todos los territorios españoles y portugueses, e incluso en las dos Indias ${ }^{53}$.

Como algunos escritos manifiestan, los hombres de negocios no sólo aprovecharon la oportunidad para extender sus negocios por los territorios de la corona, sino también para medrar en la sociedad. Lo ilustra bien una carta del rey -citada ya parcialmente- enviada a Juan Núñez Saravia ${ }^{54}$, Simón Lorenzo Perero y Payo Rodríguez, refiriéndose al primero como «Caballero hidalgo de mi casa» ${ }^{55}$.

La incorporación en España de los lusitanos de origen judeoconverso no empezó con la época de los validos (Lerma, Olivares y Luis de Haro) sino más de un siglo antes. Los judeoconversos aprovecharon la facilidad de instalarse en ambos reinos después de los claves acontecimientos de finales del siglo XV. El movimiento comercial favorecido por las vinculaciones matrimoniales y en general por los enlaces familiares entre los anusím ${ }^{56}$ se extendió con la agregación del territorio portugués a la corona española en $1580^{57}$. De tal forma que los hombres de negocios con su expandida red transatlántica se llegaron a instalar en Sevilla «en gran número a partir de $1581 »^{58}$.

Sin embargo, las transacciones entre la comunidad de ricos comerciantes lusos y la monarquía española sólo comenzaron poco después de la subida al trono de Felipe III. En concreto, en 1601, el mismo año en que se votó el servicio de los dieciocho millones ${ }^{59}$ (rechazado al principio por las poderosas diecisiete ciudades y una villa $)^{60}$. Los primeros años del nuevo siglo estuvieron determinados por diferentes intentos de conseguir dinero y subvenciones, tanto para sanear la economía, ya en vía de decadencia, como para las campañas militares. El enfrentamiento más notable en aquel momento fue probablemente el de las diecisiete provincias de los Países Bajos para independizarse del yugo español. Tal lucha se conoció como la Guerra de los ochenta años que empezó en 1568, con Felipe II en el trono. Para la corona española, esa situación de resistencia constante por parte de los territorios ocupados fue una fuente más de agotamiento económico.

Según Garrot Zambrana, salvo una alusión en El auto de las formas de Alcalá de Pérez de Montalbán, el episodio casi no aparece en el teatro (Garrot Zambrana, 2012, p. 27).

53. Pere Molas Ribalta, 1987, p. 94; Wachtel, 2011, p. 185

54. Sobre Juan Núñez Saraiva, ver la tesis de Carrasco Vázquez, 2004

55. BNE, ms. 2311, fol. 255r.

56. «De todas las palabras que definen al converso, quizá la más apropiada fuera la hebrea "anusim", que significa "el forzado"» (Gilman, 1978, p. 166).

57. Huerga Criado estudia el papel de la familia y las negociaciones de los matrimonios en relación con el orden social de los judeoconversos emigrantes de Portugal (ver Huerga Criado, 1994, pp. 55 y ss.).

58. Sanz Ayán, 1989, p. 163.

59. Domínguez Ortiz, 1984, pp. 30-32.

60. Es decir, por las oligarquías urbanas (Ruiz Martín, 2008, pp. 104-106). 
Gelabert recoge los datos de las transferencias de la monarquía al ejército de Flandes. Las cantidades de dinero dan cabida al efecto monetario de las acciones y cambios en la política fiscal al principio del siglo61. Tras bajar de 4.461.295 ducados en 1600 a 1.906.494 ducados un año más tarde, con la llegada de los banqueros portugueses, los cambios con el servicio de los millones, la retirada del vellón y las rentas extraordinarias, entre 1602 a 1605, se experimentó un incremento de 2,5 millones a 4,3 millones ducados. Al mismo tiempo, tras más de veinte años con interés de préstamo encima del diez por ciento, los asentistas genoveses lo bajaron a alrededor del nueve por ciento ${ }^{62}$, lo que no impidió que Felipe III declarara el estado de bancarrota en 1607.

Según J. I. Israel, la «invasión» de los mercantilistas y empresarios portugueses en España se explica por la débil presencia de una clase empresarial autóctona ${ }^{63}$. La monarquía española se quedó atrás durante el desarrollo comercial europeo de la segunda mitad del siglo XVI, y recurría a la ayuda de los hombres de negocios genoveses y flamencos, entre otros. Además, se añade la despoblación ocurrida en muchas ciudades castellanas y la subida de Felipe III al trono en 1598, quien, al contrario que su padre, el precedente rey contrarreformista Felipe II, se fiaba de su favorito el Duque de Lerma para gobernar. Felipe III equilibraba el peso religioso y el ideal político de razón de Estado, prefiriendo acuerdos con protestantes (marineros ingleses y holandeses) y conversos a una España en ruina económica ${ }^{64}$.

Uno de los acuerdos tuvo lugar en 1605, cuando se concedió el perdón general por el papa, y aunque fue anulado poco después, había conseguido un principio de significativa migración lusitana hacia las grandes ciudades españolas ${ }^{65}$. De tal forma, los comerciantes iudeoconversos lusos se establecieron inicialmente en

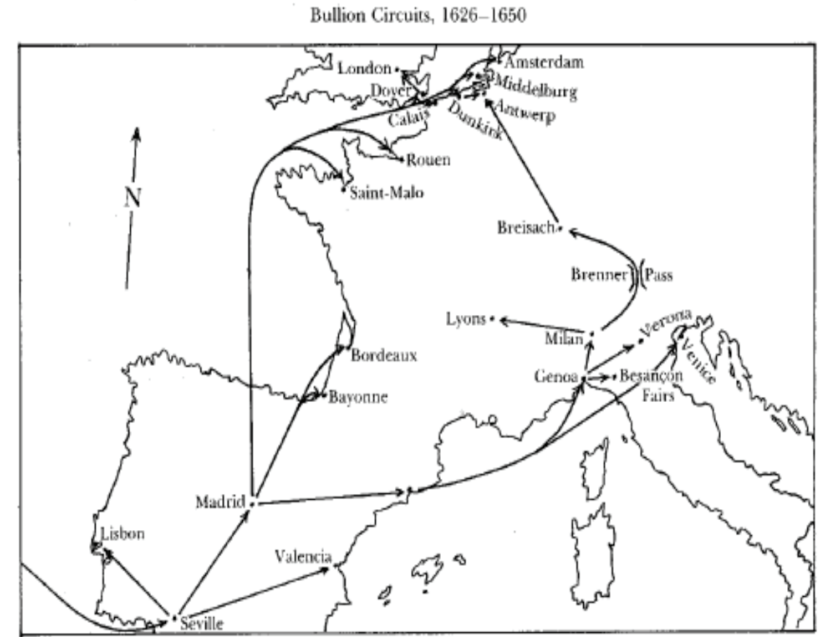

Mapa 1. Comercio de plata y oro, 1626-1650. Fuente: Boyajian, 1983, p. 95.

61. Gelabert, 1998, pp. 276-277.

62. Boyajian, 1983, p. 167.

63. Israel, 1992, p. 82.

64. Botero comenta sobre los empréstitos en el punto número cinco de La razón de Estado (Botero, La razón de Estado y otros escritos, p. 157).

65. Israel, 1992, pp. 82-83. 
Madrid, Sevilla y Málaga y se han hecho cargo del comercio de lana, importación de paños y el tráfico con las Indias. Entre 1595 y 1620 casi todo el comercio judío de Holanda se realizaba con Portugal y sus colonias, incluso importaciones de azúcar, madera de Brasil y diamantes de la India, vía Oporto y Lisboa.

\subsection{Olivares acoge a los asentistas lusitanos}

Cuando la corona española no consiguió cumplir sus plazos de devolución a los acreedores, en particular, a los banqueros genoveses, tuvo que declarar la bancarrota en 1627. Esta resolución, forzada por las circunstancias, fue la que incitó al conde duque a ejecutar su plan de sustitución sin más demora. Por ello, fue aprobado el primer Edicto de Gracia para los marranos portugueses bajo el reinado de Felipe IV. El documento expresa la disposición del gobierno español para recibir a los judeoconversos portugueses, sin ninguna distinción entre quien realmente practicaba herejía y quien era sinceramente convertido ${ }^{66}$. El edicto pronto experimentará dificultades que difuminan la ilusión de poder interactuar libremente en territorio, y que involucran los habituales prejuicios sobre el judío, el dinero y el miedo a la corrupción religiosa ${ }^{67}$.

El 31 de enero de 1627 el rey Felipe IV firmó un decreto a favor de los mercaderes lusos permitiéndoles la libertad de movimiento entre los territorios y concediéndoles ciertos privilegios. El decreto llegó a concretarse gracias a donativos de asentistas suscritos anteriormente por Felipe IV y Olivares (entre los nombres destacados formaban parte Duarte Fernández, Juan Núñez Saraiva, los hermanos Rodríguez Pasariños y más). Se hablaba de un donativo de 1.700 .000 cruzados $^{68}$ destinado a pagar parte de las múltiples deudas del gobierno. Aunque el mero hecho de mencionar su procedencia hebrea significaba que a pesar de los esfuerzos en la asimilación, no se veía a los judeoconversos de origen portugués como cristianos. Así se relata en el Decreto de V. M. el Rey Don Felipe IV en favor de los Hombres de negocios de Portugal que son de Nación Hebrea asentistas con V. M.:

Siendo necesario hacer grandes prevenciones a los estados de Flandes, Alemania y otras partes de dentro y fuera de España y para esto que la estrechura en que esta mi hacienda hacer algunos asientos con diferentes hombres de negocios y conviniendo que estos sean más en número y vasallos más y naturales de mis reinos y que les comide a ellos la seguridad y crédito de las consignaciones que se les dieron, habiéndolo mandado ver a mi confesor y teólogos graves de ciencia y conciencia, con su acuerdo he resuelto que en los asientos que se hicieren con Nuño Díaz Méndez de Brito, caballero hidalgo de mi casa, Juan Núñez Saravia, Simón Lorenzo Perero, y Payo Rodríguez se les conceda entre otras condiciones que todas las consignaciones y fueros de resguardo que de mi hacienda se dieren y señalaren [...] sean libres y no se les puedan embargar de deuda ni secuestrar, ni

66. Ver Ebben, 1993, p. 546.

67. BNE, ms. 2347, fols. 15r-16v. Según cuenta un anónimo, muchas veces no era sino una estafa burocrática en referencia al perdón general de 1601. El texto forma parte de mi tesis doctoral titulada Poder, sangre y dinero: Olivares en su laberinto (2014).

68. Aguado de los Reyes, 2009, p. 8. 
confiscar, por ningún delito aunque sea de lesa Majestad divina o humana y que se puedan ceder y traspasar con la misma calidad a cualquier persona y que puedan gozar y gocen de este privilegio [...] a 31 de enero de $1627^{69}$

Braudel afirma que los judíos mercaderes, y por extensión sus familiares portugueses, actuaban a gran escala hasta establecer un monopolio sobre distintos tipos de comercio. Aunque muchos eran pequeños prestamistas, son los comerciantes quienes han conseguido enriquecerse. Estos «Fuggers del oriente» ${ }^{70}$ se han convertido en un poder económico con cierta capacidad de influencia en asuntos políticos $^{71}$. Todo apunta a que la gran mayoría de los judeoconversos que inmigraron al territorio español no tenían una relación directa con los banqueros. Cientos de familias que se instalaron esencialmente en Sevilla y Madrid ${ }^{72}$ en dos momentos claves: en enero de 1605, después de abrir las fronteras mediante la concesión de libertad de movimiento por Felipe III73; y luego en 1629, tras una donación de 250.000 ducados $^{74}$ a Felipe IV.

La diferencia en los números entre los banqueros asentistas y el resto de la comunidad muestra que, en cierto modo, la comunidad judeoconversa funcionaba de la misma manera que sus antepasados. Es decir, desde la antigüedad la comunidad judía actuaba como una entidad donde los prósperos y afortunados contribuían al bienestar de toda la comunidad ${ }^{75}$, una mentalidad que se ha transmitido a los judeoconversos. Se trataba de la expansión de sus negocios, mediante el mundo de las finanzas y la ampliación de sus comercios existentes en forma de contratos más atractivos con mercancías variadas (telas, ceras, cueros, tabaco, sal, especias, pimienta, seda, esclavos...). No obstante, la preocupación por los suyos no fue a costa de la economía local, sino al contrario: la reciprocidad fue lo que contribuyó a la prosperidad. El paradigma por excelencia es el de Ámsterdam que mantuvo una fuerte correlación con los comerciantes y mercaderes judíos y floreció a lo largo del siglo XVII, al mismo tiempo que Madrid vivió una decadencia ${ }^{76}$.

Durante los años veinte y treinta del siglo XVII, los genoveses perdieron paulatinamente su monopolio prestamista de los españoles a favor de los hombres de negocios portugueses. Gelabert menciona que en 1623, los asientos alcanzan el máximo de contrataciones, con una suma de 12.442.764 ducados ${ }^{77}$ lo que aumen-

69. BNE, ms. 2311, fols. 255r-255v. La cita forma parte de una compilación de varios papeles referentes al conde duque de Olivares.

70. Braudel, 1987, p. 218

71. Aunque nunca consiguieron impedir los abusos contra este pueblo. Como cuenta Braudel de Italia, cada vez que una ciudad se encontraba económicamente mal, hacía venir a los judíos prestamistas, hasta que se imponía la rutina, y volvían las persecuciones, que a menudo acababa en muertos de la comunidad hebraica (Braudel, 1987, p. 217).

72. Ruiz Martín calculaba hasta dos mil negociantes en Sevilla hacia 1640 (Ruiz Martín, 1970, p. 117).

73. Varias veces pagaron a la corona (un donativo) sin que esta cumpliese el acuerdo.

74. Broens, 1989, p. 36; Ebben, 1993, p. 544; Boyajian, 1983, p. 17.

75. Para una lectura sobre la comunidad judía en España y Portugal, ver Sloan, 2009.

76. El argumento no es la única explicación de la situación, pero pudiera haber sido parte de la solución (Braudel, 1987, p. 219).

77. Gelabert, 1998, p. 279. 
taba la preferencia de bajos intereses. Por ello, el peso de los banqueros portugueses aumentó hasta finales de los años treinta y principios de los cuarenta cuando sobrepasaron la cantidad del dinero prestado por los genoveses ${ }^{78}$. Además, según el estudio de Gelabert, los años 1640 y 1642 fueron los años de préstamo más cuantioso de los mismos asentistas portugueses ${ }^{79}$. Del mismo modo, Sanz Ayán señala algunos datos donde los principales asentistas de la corona en el año 1641 y 1642 aprovechaban de un predomino con una representación de cerca del sesenta por ciento de la totalidad de los asentistas. En 1641, por ejemplo, eran siete portugueses frente a solamente dos genoveses ${ }^{80}$. Sin embargo, a partir de la retirada del conde duque en 1643 los judeoconversos perdieron paulatinamente su poder y volvieron a la sombra. Dos años después de la muerte del privado, en el año de la suspensión de pagos, se redujo la envergadura de los portugueses a una proporción de 1:7 a favor de los genoveses ${ }^{81}$. Esta tendencia siguió durante la segunda mitad del siglo. Sanz Ayán refleja mediante llamativos gráficos la disminución de inversiones lusitanas que marcaba la vuelta de los asentistas españoles ${ }^{82}$ y los banqueros genoveses (según los Avisos de Barrionuevo, los primeros empezaron ya en septiembre de $\left.1654^{83}\right)$.

\subsection{La Inquisición toma partida}

En medio de esta diatriba política, el factor que quizá tuvo más influencia sobre el futuro de los banqueros portugueses fue la continua persecución de la inquisición. Adler afirma que «the Spanish Inquisition owed its terrible efficiency to its combining the mysterious authority of the Church with the secular power of the Crown ${ }^{84}$. La Inquisición formó, para facilitar sus intervenciones, una estrecha relación entre ella y el gobierno mediante hombres poderosos que se comprometían en ambas instituciones o alternaban entre una y otra. Por ejemplo, como bien sostiene Saraiva en The Marrano Factory, la gran mayoría de los inquisidores generales eran, en su pasado o posteriormente a este deseado oficio, hombres de estado con agendas políticas interesadas ${ }^{85}$. Los casos antes y durante el gobierno olivarista son múltiples: Juan Bautista de Acevedo (Inquisidor General 1603-1608)

78. Boyajian muestra una tabla con datos recogidos del AGS, en la cual los años 1636-1646 destacan como los más significativos, sobre todo en el año 1642, con un asiento en valor de 7.327 .000 ducados (Boyajian, 1983, p. 205).

79. Junto a los años 1623, 1625-1626 (Gelabert, 1998, p. 297).

80. Las tres primeras sumas de dinero más cuantiosas eran de Jorge de Paz Silveira, Duarte Fernández y Fernando Tinoco. Los otros eran un florentino, un flamenco de Brabante y un español (tendencia que se fue acrecentando durante el tercer cuarto del siglo). Ver Sanz Ayán, 2013, pp. 131-132.

81. Jorge de Paz Silveira tuvo la mayor aportación, aunque era el único portugués. Además de los siete genoveses hubo también tres españoles, lo que igualmente indicaba el creciente número de asentistas peninsulares.

82. Sanz Ayán, 1989, pp. 163-169, muestra claramente las ondulaciones en el mercado durante la segunda mitad del siglo XVII.

83. Barrionuevo, Avisos, 1654-1668, p. 146.

84. Adler, 1908, p. 70

85. Saraiva y Salomon, Sassoon, 2001, p. 192 
era presidente del Consejo de Castilla; Bernardo de Sandoval y Rojas (Inquisidor General 1608-1618) era un pariente del Duque de Lerma, valido del rey Felipe III; Antonio Zapata y Cisneros ejerció como consejero de estado de Felipe III y virrey de Nápoles antes de recibir la posición de Inquisidor General entre los años 1627 y 1632. A partir de entonces, hasta 1643, cumplió esa función Antonio de Sotomayor, el elegido y preferido del conde duque ${ }^{86}$. El fraile dominicano no era ajeno al poder, ya que desde el año 1616 ejerció el papel de confesor real ${ }^{87}$. Presionado por Olivares, Sotomayor se mostró en estos años más indulgente con los descendientes de la nación hebrea.

Además, es posible establecer una relación entre el auge de la inmigración portuguesa que llegó en la segunda mitad de los años veinte y el nombramiento político de un inquisidor general más debilitado. Zapata y Cisneros (Inquisidor General 1627-1632) fue elegido por orden del conde duque y se convirtió, entre los inquisidores generales, en uno de los más indulgentes hacia los judaizantes. Saraiva sugiere que desde el principio del siglo XVII88, los dos poderes se iban separando hasta prácticamente contrarrestarse. Evidentemente, no se trataba de una evolución lineal, sino de fluctuaciones en el poder que se comprueban mediante las fechas de los autos de fe que coinciden con fechas de debilidad política. Eso explica las decisiones interesadas en cuanto a las actuaciones por o contra los judeoconversos. Es decir, entre Edictos de Gracia del rey y autos de fe categóricos y grandiosos existía una alternancia de interés propio.

Así que los Edictos de Gracia y los indultos suponían un incentivo influyente al garantizar una vida al margen de la persecución inquisitorial. Pese a lo que deduce López Belinchón en su estudio sobre los mercaderes portugueses ${ }^{89}$, la diferencia en el número de los relajados en autos de fe entre el valimiento de Olivares (38) frente a la segunda mitad del siglo XVII (65) muestra que el conde duque consiguió a menudo mantener a los asentistas portugueses y a sus familiares fuera del alcance de la Inquisición ${ }^{90}$. Especialmente cuando surgió una necesidad de inversiones de grandes cantidades de dinero para la financiación de las múltiples campañas militares contra Francia, Países Bajos, Cataluña y Portugal. De hecho, los graves conflictos tuvieron lugar desde el 6 de junio de 1635 hasta después de la caída del conde duque, lo que correspondía perfectamente a una llamativa calma inquisitorial.

86. Puyol Buil, 1993, p. 346

87. El deber principal de un rey es ser ante todo un buen cristiano, por lo tanto el papel de un confesor no era meramente teológico y moral, sino político. Un ejemplo relevante es el del padre jesuita Hernando de Salazar, confesor de Olivares, quien dedicó muchos de sus consejos a asuntos de la corona y a significativas decisiones políticas (ver a propósito el notable artículo de Negredo del Cerro, 2002).

88. En especial, tras el primer quinto del siglo XVII (Saraiva, 2001, pp. 214-215). Un tiempo que, según destaca Israel, había sido el auge de los comerciantes judíos y los banqueros portugueses (Israel, 1992, p. 75).

89. López Belinchón, 2001b, p. 1049.

90. Cohen, 2014 , p. 221

HIPOGRIFO, Volumen extraordinario, 1, 2018 (pp. 191-215) 
Los autos de fe solían corresponder a momentos de debilidad en el gobierno cuando era frecuente la conmutación de penas por dinero ${ }^{91}$. Caro Baroja relata el caso de la familia Saravia, en particular, de Juan Núñez Saravia, uno de los más prósperos asentistas ${ }^{92}$. En 1632 fue arrestado por la Inquisición para acabar en 1637 condenado en Auto de fe a abjuración de vehementi con multa de 20.000 ducados. Su hermano, que fue igualmente acusado y encarcelado, llegó a perder todos sus bienes ${ }^{93}$. En estas incidencias, incluso el poderoso valido tuvo que retroceder, como aparece en la correspondencia de Olivares, Felipe IV se mostró de vez en cuando más involucrado en la política, decantándose entre la influencia religiosa de rigor cristiano y las necesidades pragmáticas alineadas con su valido ${ }^{94}$. Por ejemplo, en un decreto escrito por Felipe IV, acusa el Rey Planeta a los pecados y pecadores como una de las causas de los malos sucesos que afectan a la monarquía ${ }^{95}$. Con la subida al trono de Carlos II la situación empeoró, ya que el Hechizado no solo se mostró débil delante del poder religioso, sino que su estado físico y mental incrementó la supuesta culpa de los judíos y judeoconversos. Tal situación provocó la cúspide de los autos generales de fe, como por ejemplo en 1680, que resultó en 21 relajados ${ }^{96}$.

La sugerencia de que los autos de fe fueron más que un tácito acuerdo entre el poder temporal y divino no se manifestaba solamente en el número de reos condenados, sino también en su género. De hecho, durante la etapa influyente de los banqueros lusitanos (1625-1650) se quemaban más mujeres que hombres (hasta casi el doble). Al contrario, durante la segunda mitad del siglo XVII, el balance se volvió a favor de los varones ${ }^{97}$. Este resultado concuerda con el hecho de que su papel como acreedores del reino disminuyó de forma significativa.

En suma, los banqueros portugueses no resistieron largo tiempo en el poder financiero del gobierno y a partir de los años cincuenta perdieron su posición frente a los recién surgidos asentistas españoles ${ }^{98}$. Otro antecedente posible del fracaso desde el punto de vista familiar fue la incapacidad de los banqueros de preservar una continuidad frente al miedo a la Inquisición. Aparte de los Cortizos, no se hablaba nunca de un poder familiar significativo (como en los casos de las grandes

91. Ver Domínquez Ortiz, 1984, pp. 191-199.

92. Caro Baroja, 1961, pp. 324, 326.

93. Ver Ebben, 1993, p. 551.

94. Ver Elliott y de la Peña, 1981, tomo II, pp. 37-38. En la carta Felipe IV muestra su pensamiento estratégico en asuntos de política exterior.

95. BNE, ms. 2361, fol. 522r. Forma parte de Un decreto de S. M., escrito de su real mano para el Consejo sobre el estado de las cosas en que se halla la Monarquía, en el libro de los sucesos del año de 1629. 96. Paradójicamente, con esta nueva ola de antisemitismo, la segunda mitad del siglo XVII está considerada como el tiempo que anunció el bienestar para los judíos. Israel incluso llama a este fenómeno «la corriente de filosemitismo». Aunque se reconoce que se trata principalmente de la Europa septentrional (Israel, 1992, pp. 261-273).

97. Cohen, 2014, p. 224.

98. Históricamente hablando, según las cifras de Gelabert en su artículo sobre los gastos de la monarquía, los años 1623, 1625-1626, 1640, 1642 fueron aquellos con el préstamo más cuantioso de los asientos (Gelabert, 1998, p. 297). 
familias cristianas de casas comerciales centralizadas: Fuggers, Medici, Peruzzi, Bardi, Doria, Grimaldi... ${ }^{99}$, pues muchos tenían un familiar acusado, relajado o penalizado por un delito cualquiera.

\subsection{Prejuicios y respuestas}

Una de las causas del descontento popular fue la dudosa reputación de los comerciantes judeoconversos como contrabandistas, tanto en el comercio transatlántico como en el europeo. Por su lado, López Belinchón insinúa que los conversos controlaban exclusivamente el comercio de contrabando en la zona norte de la Península. El investigador sostiene que se trata de conversos de origen portugués, procedentes de la «tierra de conversos» ${ }^{100}$ refiriéndose a Vila Flor y Trancoso, Bragança, La Guarda, Lamego o San Juan de la Pesquera de las comarcas de Trásos-Montes y la Beira interior. Su apoyo principal para estas conclusiones son los procesos inquisitoriales para mencionar el daño que causaban los comerciantes judeoconversos en su rol de vínculo comercial'01.

Sin embargo, recientes investigaciones muestran que quizá se trate de un error común de perspectiva ${ }^{102}$. Las transacciones con judíos o judeoconversos no eran sino una parte reducida de la red ilegal, considerablemente más desarrollada. Escobedo ha conseguido mostrar que, en Pamplona, ciudad central en la ruta de los bienes lícitos en manos de los contrabandistas, los que controlaban este negocio lucrativo eran en su gran mayoría españoles autóctonos (en este caso navarros) ${ }^{103}$. De hecho, datos del Archivo General de Navarra (AGN) apuntan precisamente a esta conclusión. Así, de 185 referencias de procesos relacionados con el contrabando durante los siglos XVI y XVII, sólo cuatro están evidentemente vinculados a judeoconversos de origen portugués ${ }^{104}$. Durante el año 1630 se dio un crecimiento desproporcional de procesos delatando el contrabando en la zona, y entre los once procesos registrados dicho año, los acusados eran cristianos vascos, franceses y navarros ${ }^{105}$. De este modo, hasta los mismos soldados colocados en la zona (dada la constante tensión con Francia) disfrutaban de un beneficio mediante su cooperación con los locales, a pesar de que legalmente estaba vigente el castigo ${ }^{106}$.

99. Le Goff, 1991, p. 25, utiliza el nombre de compañías en su sentido moderno actual.

100. López Belinchón, 2001b, p. 1024.

101. López Belinchón, 2001b, p. 1025. Los ejemplos son múltiples, pero entre los más destacados están: Juan Rodríguez Lamego, cuñado de Enrique Núñez Saravia (hermano de Juan Núñez Saravia, Bartolomé Febo, Antonio Núñez Torres (suegro de los hermanos Antonio y Pedro Fernández Pato), y, por último, Diego Rodríguez de Acosta quien era pariente de los Tinoco, de los últimos poderosos asentistas portugueses.

102. López Belinchón se concentra en las redes de comercio entre las comunidades conversas y particularmente portuguesas (López Belinchón, 2001a. En particular, p. 70 en adelante).

103. Escobedo, 2003, p. 317.

104. Procesos en contra de Luis de Castro y Álvaro de Luis, Álvaro Pérez y Méndez, Diego de Andrada y sus socios, Francisco de Rozas y Luis Álvarez.

105. AGN, procesos de los Tribunales Reales de Navarra.

106. García Pérez et al., 2011, p. 81. 
García Zúñiga también menciona a los eclesiásticos que realizaban tráfico ilegal por Navarra, Castilla y Aragón, aprovechando, para ello, el disimulo de su vestido ${ }^{107}$.

Desde el punto de vista económico, quizá el detalle que más afectó a la situación del contrabando fue la tasa de cambio. La depreciación de la moneda local puede producir la subfacturación de la exportación que, a su vez, disminuye la cantidad de subfacturación de la importación ceteris paribus. Por ende, se destaca una correlación entre las bancarrotas y la drástica bajada en la tasa de cambio; un aumento de importación de productos de contrabando debía afectar el comercio con moneda extranjera, que, a su vez agitó de nuevo la situación económica, agravando la crisis y ampliando su duración ${ }^{108}$. Decididamente, parece que la razón por la cual se registra un aumento masivo en el contrabando esos años se vincula ex profeso con la devaluación monetaria y la considerable inflación provocada por ella. Es decir, las denuncias y acusaciones fueron en el año 1629, entre cuatro y doce meses después de la bajada del vellón (agosto de 1628). Por tanto, es más prudente afirmar que el contrabando (por lo menos en el norte de España) creció respondiendo a la necesidad de productos con precios del mercado negro.

Un caso es el de Payo Rodríguez de Paz, uno de los principales arrendadores de tabaco, un negocio que creció de forma espectacular tras la colonización del Nuevo Mundo. Éste se relacionaba con Diego Gómez Salazar, un administrador de tabaco de la misma procedencia judeoconversa para el bien de su comercio ${ }^{109}$. Otra actividad clave era la gestión de impuestos y el tráfico mercantil, en la que tomaban parte Francisco Coello, Jiménez de Aragón y Juan Núñez Correa, entre otros (todos judeoconversos). Del mismo modo, los hermanos García Yllán, que, pese a las prohibiciones de viajar a las Indias para los judeoconversos, consiguieron partir e incluso comerciar en esta zona ${ }^{110}$.

Nicolás Broens escribió sobre la red de Bartolomé Febo, entre Ámsterdam, Rouen y España ${ }^{111}$. Broens recalca la importancia del comercio de la lana en las redes de los marranos portugueses García Yllán, Manuel de Cortizos y Simón de Fonseca ${ }^{112}$. Destaca una facilidad de comercio (y quizá preferencia) entre los lusitanos ${ }^{113}$.

107. García-Zúñiga, 2006, pp. 109-110. Se refiere particularmente al contrabando del tabaco, uno de los comercios más extendidos cuyo estanco fue aprobado por las Cortes de Castilla en 1636.

108. Boyajian proporciona en su libro datos cuantitativos que muestran y apoyan estas conclusiones (Boyajian, 1983, p. 167).

109. García de Torres, 1875, p. 181. Para una historia paralela sobre los mercaderes de tabaco, ver la de Rodrigo Núñez de Silva en Caro Baroja, 1961, p. 462.

110. Incluso fueron acompañantes de la reina Cristina de Suecia en su paso por Ámsterdam (Broens, 1989, p. 64).

111. Broens, 1989, p. 54. En particular su relación con la red comercial de Juan Núñez de Saraiva (p. 61).

112. Broens, 1989, pp. 28-29.

113. Por su muerte precipitada, el trabajo de Broens se vio interrumpido. Ebben lo retoma en 1996c. 
Una de las historias más interesantes es la de la familia de los Cortizos ${ }^{114}$. Sanz Ayán sigue las huellas de esta familia judeoconversa y sus inversiones en comercio y asientos ${ }^{115}$. Un caso destacado es el de Manuel Cortizos de Villasante, hijo de Luisa de Almeida y Antonio López Cortizos, mercader importador de telas de lujo, piedras preciosas y lana. Los padres se establecieron en Madrid en la segunda mitad del siglo XVI. Su ascenso social se apoya en una estrecha relación con la política. La infraestructura de los Cortizos (en particular Manuel y sus dos hermanos) incluyó un número elevado de poderhabientes repartidos como corresponsales por toda la Península, además de Nápoles, Amberes y Ámsterdam (con una mayoría en la propia Castilla).

De hecho, los Cortizos formaban parte de los pocos banqueros judeoconversos mencionados explícitamente en la poesía satírica de la época. Un epigrama escrito contra ellos quizá fuese el primer asunto que enfadó al conde duque e inició la enemistad entre él y Adam de la Parra.

$$
\begin{aligned}
& \text { Por la monja el desafío } \\
& \text { salió el Justicia Mayor } \\
& \text { con Contreras, iqué valor } \\
& \text { digno de un morisco brío! } \\
& \text { Uno y otro lo judío } \\
& \text { desmienten con esta acción. } \\
& \text { No es muy grande el milagrón, } \\
& \text { pues con áureos bebedizos, } \\
& \text { ya han purgado los Cortizos } \\
& \text { en la Santa Inquisición }{ }^{116} \text {. }
\end{aligned}
$$

En definitiva, más que el contrabando, los mercaderes y banqueros judeoconversos recurrieron al uso e influencia del poder para mejorar sus condiciones. Gran parte de la polémica que les rodeó tuvo su origen en el trato privilegiado que algunos banqueros portugueses y sus familiares disfrutaron gracias a la política económica del privado. Las dificultades inherentes en los objetivos de los judeoconversos por un lado y de Olivares por otro no pudieron evitar el malestar social. Las repetidas persecuciones inquisitoriales pusieron de manifiesto lo difícil y complejo que resultaba superar este capítulo de la historia de España. El reino español no se recuperó de su larga decadencia y los judeoconversos no tuvieron la posibilidad de afianzar nuevas sedes comerciales en las grandes metrópolis españolas.

114. Ya desde el siglo XIV ciertas familias de mercaderes han conseguido desarrollar una extensa y poderosa red con complejos mecanismos en forma de compañías. Así eran algunas potentes familias italianas: Ios Peruzzi, los Bardi, los florentinos Médicis y más (Le Goff, 1991, p. 25). Con esta noción de red con enlaces familiares crecieron los Cortizos.

115. Sans Ayán, 2004, pp. 185-209.

116. Adam de la Parra, Conspiración herético-cristianísima, p. XXVI. 


\section{BIBLIOGRAFÍA}

Adam de la Parra, Juan, Conspiración herético-cristianísima, trad. Ángeles Roda Aguirre, Madrid, CSIC, 1943.

Adler, Elkan N., Auto de Fe and Jew, London/ Edinburgh/Glasgow/New York/Toronto, Oxford University Press, Henry Frowde, 1908.

Aguado de los Reyes, Jesús, «Los portugueses de la nación en Sevilla en tiempos del Conde Duque», presentación en la XXIX Conference of the Potuguese Association of Social and Economic History, Social Memory, Heritage and Identities, Porto, Universidad de Porto, 2009.

Barrionuevo, Joaquín, Avisos, 1654-1668, Madrid, Imprenta y fundición de Manuel Tello, 1892.

Borrego Pérez, Manuel, «Olivares, un valido reformista», en L'Espagne de validos 1598-1645, ed. Rudy Chaulet, Paris, Ellipses, 2009, pp. 71-108.

Botero, Giovanni, La razón de estado y otros escritos, trad., notas y bibliografía Luciana de Stefano, estudio preliminar Manuel García Pelayo, Caracas, Instituto de Estudios Políticos, Universidad Central de Venezuela, 1962.

Boyajian, James C, Portuguese Bankers at the court of Spain 1626-1650, Rotgers, The State University of New Jersey, 1983.

Braudel, Fernand, El Mediterráneo y el mundo Mediterráneo en la época de Felipe II, trad. Mario Monteforte Toledo, Wenceslao Roces y Vicente Simón, México, FCE, 1987.

Broens, Nicolás, Monarquía y capital mercantil: Felipe IV y las redes comerciales portuguesas (1627-1635), Madrid, Universidad Autónoma, 1989.

Cánovas del Castillo, Antonio, Historia de la decadencia de España desde el advenimiento de Felipe III al trono hasta la muerte de Carlos II, Madrid, Librería Gutenberg de José Ruiz, 1910.

Caro Baroja, Julio, Los judíos en la España moderna y contemporánea, Madrid, Arion, 1961.

Carrasco Vázquez, Jesús A., La minoría judeoconversa en la época del Conde Duque de Olivares. Auge y ocaso de Juan Núñez Saravia (1585-1639), tesis doctoral inédita bajo la dirección de Jaime Contreras Contreras, Universidad de Alcalá, 2004.

Castro, Adolfo de, Historia de los judíos en España: desde los tiempos de su establecimiento hasta principios del presente siglo: obra escrita e ilustrada con varios documentos rarísimos, Valencia, Librerías «París-Valencia», 1992.

Cavillac, Michel, «Del erasmismo al "efecto" Botero: la utopía española del trabajo en torno a 1600», en Modelos de vida en la España del Siglo de Oro, tomo I: El 
noble y el trabajador, coord. Ignacio Arellano y Marc Vitse, Madrid/Frankfurt, Iberoamericana/Vervuert, 2004, pp. 273-287.

Cohen, Shai, «Entre sátira y política, la figura del arbitrista en el siglo XVII», en Pictavia aurea. Actas del IX Congreso de la Asociación Internacional «Siglo de Oro», (Anejos de Criticón, 13), ed. Alain Bègue y Emma Herrán Alonso, Toulouse, Presses Universitaires du Mirail, 2013, pp. 1223-1232.

Cohen, Shai, Poder, sangre y dinero: Olivares en su laberinto, tesis doctoral inédita bajo la dirección de Ignacio Arellano, Universidad de Navarra, 2014.

Colmeiro Penido, Manuel, Historia de la economía política en España [1863], Madrid, Taurus, 1965, 2 vols.

Contreras, Jaime, Ignacio Pulido y Rafael Benítez, Herejes, judíos y moriscos, Barcelona, Debolsillo, 2005.

Dedieu, Jean-Pierre, «Procesos y redes, la historia de las instituciones administrativas de la época moderna, hoy», en La pluma, la mitra y la espada: estudios de historia institucional en la Edad Moderna, ed. Jean-Pierre Dedieu, Juan Luis Castellano y M. ${ }^{a}$ Victoria López-Cordón Cortezo, Madrid, Marcial Pons Historia, 2000, pp. 13-30.

Díez Borque José M.a, «Teatro de palacio: excesos económicos y protesta pública», en Literatura, política y fiesta en el Madrid de los Siglos de Oro: Congreso Internacional «Literatura, Política y Fiesta en el Madrid de los Siglos de Oro», coord. Esther Borrego Gutiérrez, Catalina Buezo y José María Díez Borque, Madrid, Visor, 2009, pp. 43-78.

Domínguez Ortiz, Antonio, Política fiscal y cambio social en la España del siglo XVII, Madrid, Instituto de Estudios fiscales, 1984.

Dubois, Auguste, Précis de l'histoire des doctrines économiques dans leurs rapports avec les faits et avec les institutions, Genève, Slatkine Reprints, 1970.

Ebben Mauricio, «Un triángulo imposible: la Corona Española, el Santo Oficio y los banqueros portugueses, 1627-1655», Hispania, 53, 2, 1993, pp. 541-556.

Elliott, John H., El conde duque de Olivares, el político en una época de decadencia, Barcelona, Crítica, 1991.

Elliott, John H. y José F. de la Peña, Memoriales y cartas del Conde Duque de Olivares. Política interior 1621-1645, Madrid, Alfaguara, 1978-1981.

Escobedo, Rafael, «Sospechosos habituales: contrabando de tabaco y comerciantes extranjeros en los puertos españoles», en I Coloquio Internacional «Los Extranjeros en la España Moderna», dir. M. ${ }^{a}$ Begoña Villar y Pilar Pezzi Cristóbal, Málaga, tomo I, 2003, pp. 313-323.

García Cárcel, Ricardo, La Inquisición, Madrid, Anaya, 1997.

García de Torres, Juan, «El tabaco: consideraciones sobre el pasado, presente y porvenir de esta renta», Revista de España, 47, 1875, pp. 173-196. 
García Guerra, Elena M. ${ }^{a}$, «Entre la teoría y la práctica, El pensamiento arbitrista castellano durante la edad moderna en Castilla», en V Jornadas Científicas sobre documentación de Castilla e Indias en el siglo XVII, Madrid, Departamento de Ciencias y Técnicas Historiográficas, Universidad Complutense de Madrid, vol. V, 2006, pp. 183-205.

García Guerra, Elena M. ${ }^{\text {a }}$, «La moneda de vellón: un instrumento al servicio de la fiscalidad del Estado moderno castellano: las Cortes», Cuadernos de Historia Moderna, 21, 1998, pp. 59-101.

García Pérez, M. ${ }^{a}$ Isabel, y Jéssica Zubiría Ortega, «Soldados y población en la Navarra de la primera mitad del siglo XVI», Príncipe de Viana, 254, 2011, pp. 7987.

García-Zúñiga, Mario, «El estanco del tabaco en Navarra, 1642-1841. Valores, consumo y contrabando», en Gerónimo de Uztariz, 22, 2006, pp. 107-139.

Gelabert González, Juan Eloy, «La evolución del gasto de la Monarquía Hispánica entre 1598 y 1650, Asientos de Felipe III y Felipe IV», Studia historica, Historia moderna, 18, 1998, pp. 265-298.

Gutiérrez Nieto, Juan Ignacio, «El pensamiento económico, político y social de los arbitristas», en Historia de España, XXVI, Historia de la Cultura Española: «El siglo del Quijote», dir. Ramón Menéndez Pidal, Madrid, Espasa-Calpe, 1996, vol. I, pp. 235-351.

Hamilton, Earl J., El florecimiento del capitalismo, ensayos de historia económica, Madrid, Alianza, 1984.

Hernández, Bernat, «Infortunas del imperio español. Real Hacienda, finanzas y veIlón, 1598-1643», en L'Espagne de validos 1598-1645, ed. Rudy Chaulet, Paris, Ellipses, 2009, pp. 21-34.

Huerga Criado, Pilar, En la raya de Portugal: solidaridad y tensiones en la comunidad judeoconversa, Salamanca, Universidad de Salamanca, 1994.

Israel, Jonathan I., La judería europea en la era del mercantilismo, 1550-1750, Madrid, Cátedra, 1992.

Israel, Jonathan I., «The Sephardi Contribution to Economic Life and Colonization in Europe and the New World (16th-18th Centuries)», en Moreshet Sepharad: The Sephardi Legacy, ed. Haim Beinart, Jerusalem, Hebrew University of Jerusalem, 1992, vol. 2, pp. 365-398.

Lapeyre, Henri, Simon Ruiz et les asientos de Philippe II, Paris, Librairie Armand Colin, 1953.

Le Goff, Jacques, Mercaderes y banqueros de la Edad Media, Barcelona, Oikos-tau, 1991.

León Tello, Pilar, Judíos de Toledo, Madrid, CSIC, 1979. 
Leroy, Béatrice, «L'image du Juif dans la littérature castillane des XIVe-XVe siècles», en 1492, l'expulsion des Juifs d'Espagne (Les Quatre Fleuves), dir. Roland Goetschel, Paris, Maisonneuve et Larose, 1995, pp. 101-109.

López Belinchón, Bernardo J., Honra, libertad y hacienda (hombres de negocios y judío sefaradíes), Alcalá, Servicio de Publicaciones de la Universidad de Alcalá/Dilex, 2001a.

López Belinchón, Bernardo J., «"Sacar la sustancia al reino". Comercio, contrabando y conversos portugueses, 1621-1640», Hispania: Revista española de historia, 61, 209, 2001b, pp. 1017-1050.

Lozano, Jiménez, Sobre judíos, moriscos y conversos, Convivencia y ruptura de las tres castas, Madrid, Ámbito Alarife, 2002.

Marques de Oliveira, António Henrique, History of Portugal, New York, Columbia University Press, 1972.

Molas i Ribalta, Pere, «Instituciones y comercio en la España de Olivares», Studia historica. Historia moderna, 5, 1987, pp. 91-97.

Nahon, Gérard, «From New Christians to the Portuguese Jewish Nation in France», en Moreshet Sepharad. The Sephardi Legacy, ed. Haim Beinart, Jerusalem, Magnes Press, 1992, pp. 336-364.

Negredo del Cerro, Fernando, «La hacienda y la conciencia. Las propuestas del confesor del Conde Duque para el saneamiento de las finanzas reales (1625)», Cuadernos de Historia Moderna, 27, 2002, pp. 171-196.

Palacio Atard, Vicente, España en el siglo XVII: derrota, agotamiento, decadencia, Madrid, Rialp, 1987.

Pimenta Ferro Tavares, M. ${ }^{a}$ José, Los judíos en Portugal, Madrid, MAPFRE, 1992.

Poliakov, Léon, Les banquiers juifs et le Saint-Siège du XIIIe au XVIIe siècle, Paris, Calmann-Lévy, 1965.

Rabid, Benjamin, «La dernière charte des marchands juifs du levant et du ponant à Venise, 1711 », en 1492 L'expulsion des juifs d'Espagne, ed. Roland Goetschel, Paris, 1996, Maisonneuve et Larose, pp. 75-82.

Roth, Cecil, A History of the Marranos, New York, Schocken, 1974.

Ruiz Martín, Felipe, La banca de España, una historia económica, Madrid, Banco de España, 1970.

Ruiz Martín, Felipe, Pequeño capitalismo gran capitalismo, Simón Ruiz y sus negocios en Florencia, Barcelona, Crítica, 1990.

Ruiz Martín, Felipe, Las finanzas de Castilla y la Monarquía Hispánica (siglos XVIXVII): homenaje a Felipe Ruiz Martín, coord. Pedro Tedde de Lorca, Valladolid, Universidad de Valladolid, 2008. 
Sáenz-Badillos, Ángel, «El pensamiento económico judío durante la Edad Media», en Mediterráneo económico, 9, (Ejemplar dedicado a: Variaciones sobre la historia del pensamiento económico mediterráneo, coord. Pedro Schwartz Girón), Almería, Caja Rural Intermediterránea, Instituto de Estudios Socioeconómicos de Cajamar, 2006, pp. 117-133.

Sampson, Anthony, The Money Lenders: Bankers and a World in Turmoil, New York, Viking Press, 1982.

Sanz Ayán, Carmen, Los banqueros de Carlos II, Valladolid, Universidad de Valladolid/Secretariado de Publicaciones, 1989.

Sanz Ayán, Carmen, Los banqueros y la crisis de la Monarquía Hispánica de 1640, Madrid, Marcial Pons Historia, 2013.

Saraiva, António José y Herman P. Salomon, The Marrano Factory: the Portuguese Inquisition and its New Christians 1536-1765, Brill, Leiden, 2001.

Sloan, Dolores, The Sephardic Jews of Spain and Portugal: Survival of an Imperiled Culture in the Fifteenth and Sixteenth centuries, Jefferson, N.C., McFarland \& Co., 2009.

Soyer, François, The Persecution of the Jews and Muslims of Portugal, King Manuel I and the End of Religious Tolerance (1496-7), Boston, Leiden, 2007.

Studnicki-Gizbert, Daviken, "La "nation portugaise". Réseaux marchands dans l'espace atlantique à l'époque moderne», Annales. Histoire, Sciences Sociales, 3, 2003, pp. 627-648.

Wachtel, Nathan, «The "Marrano" Mercantilist Theory of Duarte Gomes Solis», The Jewish Quarterly Review, 101, 2, 2011, pp. 164-188.

Weber, Max, La ética protestante y el espíritu del capitalismo, Barcelona, Orbis, 1985. 
